\title{
perifèria
}

Número 6, Julio 2007

www. periferia. name

\section{Relaciones y experiencias de los gitanos y los rom con la escuela. Una aproximación comparativa ${ }^{1}$}

\author{
Bálint Ábel Bereményi ${ }^{2}$, Grupo de Investigación EMIGRA ${ }^{3}$, UAB.
}

\section{Resumen}

Este artículo presenta las similitudes y diferencias entre las estrategias y prácticas escolares de dos grupos de gitanos. A partir del trabajo de campo etnográfico realizado con gitanos de Badalona (España) y con rom de Bogotá (Colombia), y en las respectivas escuelas, se analizan algunas condiciones sociales y políticas que conducen a prácticas escolares aparentemente semejantes entre gitanos y rom, mientras las razones subyacentes demuestran diferencias substanciales. El artículo así mismo ofrece un marco de análisis del problema basado en la teorías norteamericanas desarrolladas por antropólogos de la educación.

Palabras clave: educación, gitanos, rom, etnografía.

\begin{abstract}
This article examines some similarities and differences between schooling strategies and practices of two Gitano/Rom groups. Based on ethnographic field work carried out with Gitano in Badalona (Spain) and with Rom in Bogotá (Colombia) as well as in the corresponding local schools, I will analyse some social and political conditions that lead to apparently similar schooling strategies in those communities, while underlying motives show significant differences in it. Moreover, I will also allude to within group variability. The article proposes some elements of a wider analytical framework in order to approach our issue.
\end{abstract}

Key words: education, gypsies, rom, ethnography.

\section{I ntroducción}

Aunque la totalidad de los niños y niñas gitanos de Badalona (Cataluña) están escolarizados en la escuela primaria, a lo largo de los años se les presentan más dificultades y mayor desigualdad escolar que al resto de la población estudiantil. Este fenómeno culmina al empezar la ESO cuando la inmensa mayoría de los niños

\footnotetext{
${ }^{1}$ El presente artículo, con algunas modificaciones, se presentó en la XII Conferencia de Sociología de la Educación, Universidad de La Rioja, Logroño, 14-16 de septiembre de 2006 “La educación en un tiempo de cambio social acelerado".

${ }^{2}$ Enviar correspondencia a: Bálint Ábel Bereményi, abel.beremenyi@uab.es

${ }^{3}$ Directora: Dra. Sílvia Carrasco Pons
} 


\section{perifèria}

Número 6, Julio 2007

www.periferia.name

y niñas gitanos será absentista, mostrará un bajo rendimiento y abandonará el sistema educativo.

Por otro lado, en Bogotá (Colombia) una comunidad rom-Kalderash4 (gitana) comparte representaciones y actitudes conservadoras en relación con la escuela, sobre todo con respecto a las niñas. El alumnado rom muestra una cierta tendencia absentista, estudia relativamente bien, pero abandona la escuela entre el cuarto y el séptimo grado.

El modelo cultural de las dos comunidades gitanas/rom es aparentemente similar, pero realmente ¿se trata del mismo fenómeno en Badalona y en Bogotá?

Este artículo - basado en trabajos de campo etnográficos de 20 meses en Badalona y 5 en Bogotá respectivamente - busca las diferencias en los modelos culturales frente a la escuela que los rom de Bogotá y los gitanos de Badalona han desarrollado en su propio contexto histórico y sociocultural. El modelo ecológicocultural de John U. Ogbu y su clasificación de las minorías en voluntarias e involuntarias me ha resultado útil en el caso de los gitanos de Badalona, pero la clasificación dicotómica resulta menos aplicable en los rom-Kalderash de Bogotá en un contexto social históricamente estratificado con base "racial"/étnica.

A continuación presentaré, en primer lugar el caso de la comunidad gitana en Badalona y sus reacciones ante la escuela, y a continuación el caso bogotano, en el cual los rom, bajo las influencias particulares de la sociedad colombiana, variaron su estrategia hacia la educación gadyí5.

En la comparación pretendo acentuar posibles explicaciones y algunas dudas acerca de la similitud y la diferencia entre los modelos culturales elaborados en contextos diferentes, siempre teniendo en cuenta la gran diversidad interna de ambas comunidades.

\footnotetext{
4 rom: en lengua romaní significa "hombre gitano"; Kalderash es uno de los grupos rom más numerosos de Europa de Este.

${ }^{5}$ gadyó: no gitano en lengua romaní con ortografía utilizada en la literatura colombiana. En plural: gadyé. En femenino: gadyí. (otra forma de decirlo por los rom colombianos: "particular")
} 


\section{perifèria}

Número 6, Julio 2007

www. periferia. name

\section{Casos}

\section{El caso de Badalona}

La etnografía escolar durante un año académico y la convivencia6, a priori y a posteriori, con los gitanos de Badalona ha permitido comprobar lo que la mayoría de la literatura constata: los alumnos y alumnas gitanos españoles muestran bajo rendimiento académico; son absentistas ya en la Primaria; el desgranamiento de la escuela alcanza niveles altos sobre todo en Secundaria; pocos alumnos llegan al bachillerato y a lo largo de estos años tienen menos éxito académico que otros alumnos y alumnas.

El barrio, llamémoslo San Agustino, se construyó en los sesenta para dar respuesta rápida al chabolismo y a la falta general de viviendas después de una catastrófica inundación alrededor de la capital catalana. A raíz de la pobreza y el desempleo en el barrio se presentaron diversas formas de delincuencia, entre otras el tráfico de drogas, que ha conducido a una convivencia, a veces, conflictiva entre payos7 y gitanos. El número de gitanos de la zona se estima entre 3.600 y 5.000 , que representa, aproximadamente, entre la tercera y la cuarta parte de la población total.

Las infraestructuras del barrio siempre han estado menos desarrolladas que las del resto del municipio. Esto se aplica también a la cobertura escolar. Durante bastantes años, San Agustino no tenía escuela pública, aunque sí una privada de monjas. La primera escuela pública, albergada en un barracón, se transformó en una escuela de gitanos, que más tarde se recalificó, oficialmente, como escuela puente. La segregación étnica es una dificultad con la cual varios centros han tenido que enfrentarse en el pasado y en el presente. Actualmente, en el Instituto de Educación Secundaria Ausiàs March - el centro donde se llevó a cabo la investigación - más de la mitad de los grupos clase se componen de alumnos gitanos o extranjeros, como se puede ver en el Gráfico 1.

\footnotetext{
6 El autor durante 20 meses alquiló una habitación en un barrio popularmente llamado “barrio de gitanos", en Badalona.

${ }^{7}$ payo: no gitano, utilizado por gitanos españoles
} 


\section{perifèria}

Número 6, Julio 2007

www.periferia.name

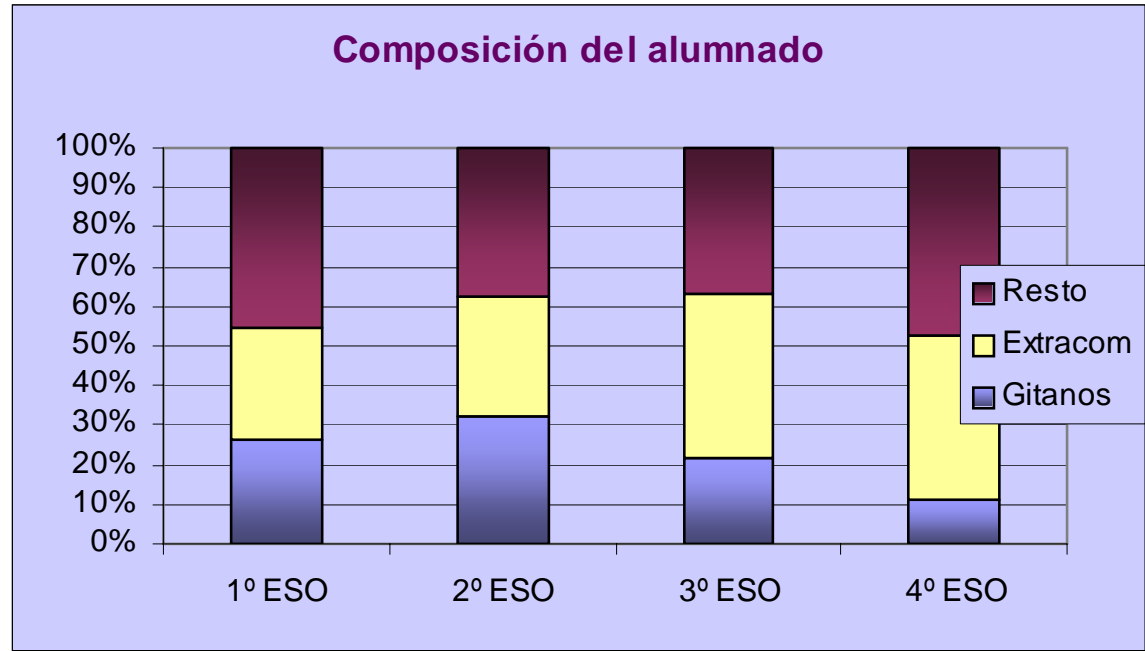

Gráfico 1: Porcentaje del alumnado gitano, extracomunitario y resto en los cuatro niveles de la ESO en el IES observado (2003-04). Fuente: Estadística escolar. Elaboración propia.

Uno de los fenómenos más destacados respecto al alumnado gitano y la escuela es el absentismo, a pesar de la obligatoriedad de los estudios, hasta los 16 años. Un estudio del Ajuntament de Badalona en 20038 concluye que el nivel de absentismo en las escuelas de infantil y primaria ( $\mathrm{P}-3$ a 60 ) del barrio alcanza un nivel del $30,5 \%$, mientras que el mismo indicador en la educación secundaria es del 38,5\%, del cual una cifra importante se refiere a los niños y niñas gitanos. 9 En el Gráfico 2 se puede observar el absentismo desproporcionado de los gitanos, que en el segundo ciclo (tercero y cuarto año) de la ESO intensivamente se combina intensivamente con el desgranamiento masivo de este alumnado.

\footnotetext{
${ }^{8}$ Fernández Moriel, Àngels (2003) Projecte de millora del procés d'atenció a l'absentisme escolar a la Zona IV de Serveis Personals - Badalona: Ajuntament de Badalona

9 tanto la entrevista realizada con la autora del estudio referido, como las observaciones propias del trabajo de campo conducen a esta afirmación
} 


\section{perifèria}

Número 6, Julio 2007

www. periferia. name

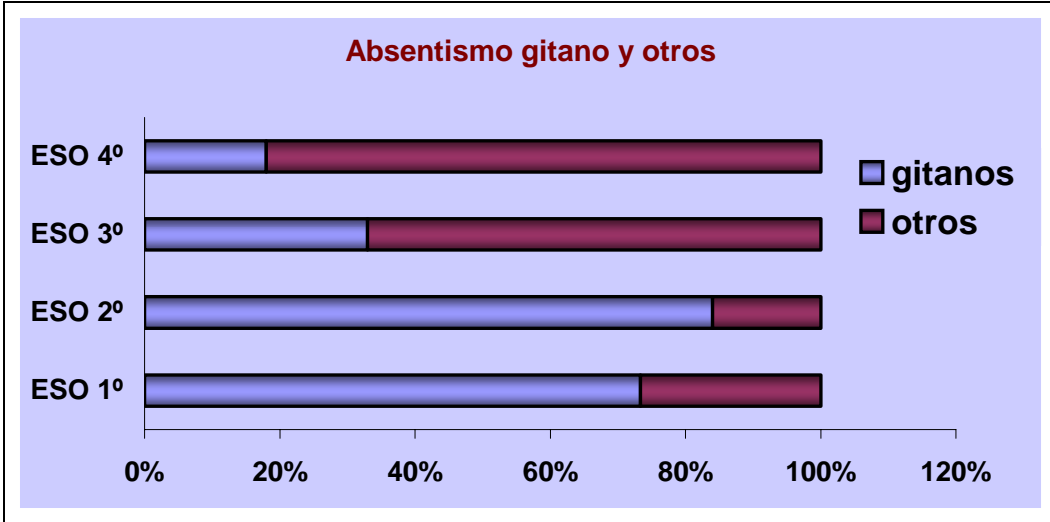

Gráfico 2: Absentismo del alumnado gitano vs. el resto del alumnado en el IES observado (2003 - 04). Fuente: estadística escolar. Elaboración propia

El absentismo y sus consecuencias no son los únicos fenómenos que dificultan el buen rendimiento y el seguimiento de los estudios del alumnado gitano. Los maestros, profesores y educadores a menudo se refieren al comportamiento asocial y disruptivo, la falta de motivación y a una actitud pasiva hacia la mayoría de las actividades escolares. La etnografía escolar ha hecho posible comprobar la existencia de estos problemas, aunque no las causas a través de las cuales los maestros, profesores, educadores y algunos políticos los explican. En otro momento (Bereményi 2004, 2005, 2007) he mencionado las interpretaciones erroneas de los profesores sobre las fuentes de esta problemática, como por ejemplo la familia "irresponsable y poco motivadora"; la cultura gitana; los niños mismos, por su actitud negativa y comportamiento disruptivo; la legislación educativa continuamente cambiante o la administración educativa municipal y autonómica.

\section{Representación de los gitanos}

En cuanto a los padres y madres gitanos, al contrario que la opinión general, ellos dicen tener expectativas positivas hacia los estudios. Esta afirmación generalizada se ha recogido por varios investigadores (San Román 1980, Abajo 1997, Vargas y Gómez 2003; Abajo y Carrasco 2004, Sánchez Aroca 2005, Méndez López 1999, 2005; Koheslan 2007, etc.). Durante mi trabajo de campo todos los informantes gitanos adultos han reconocido que la escuela es importante. Los padres y madres saben y afirman que "sin estudios no hay futuro". Destacan que las actividades productivas presentes no son sostenibles debido a la competencia, y que sólo unos 


\section{perifèria}

Número 6, Julio 2007

www.periferia. name

pocos podrán vivir bien de éstas. Al mismo tiempo, se niegan a obligar a los niños y niñas a seguir los estudios si ellos no lo quieren.

La mayoría de los padres no tiene estudios más allá de lo básico, pero muchos afirman que si fueran jóvenes irían a la escuela, porque ahora ya ven la utilidad del "conocimiento", e incluso, algunos opinan que "sin estudios no eres nadie". Varios de ellos han realizado estudios siendo ya adultos. Uno aprendió a leer y escribir para sacarse el carné de conducir, a otro se le abrió el "mundo del conocimiento escrito" a través de los estudios bíblicos, y a un tercero le obligaron las circunstancias laborales... Enrique, un anciano gitano, explica su gran sueño de volver a nacer:

...si yo naciera de nuevo yo no sería lo que soy. Yo quiero saber, saber inglés, francés, una buena carrera, abogado, ser alguien en la vida, donde me pueda defender y defender mis derechos, y donde pueda estar, y darle a mis hijos lo mismo que yo, y... una relación de mis hijos con gente más equilibrada. Que mi hijo se casara con una maestra de escuela, que la otra se casara con un médico, y... esa era mi ilusión. No lo he conseguido yo esa ilusión. Por lo tanto yo... no me importaba a mí la gente, a mi no me importaban los gitanos.

Actualmente hay un acuerdo general entre los gitanos de San Agustino - al menos en su discurso - por el que los padres y madres que no llevan a sus hijos a la escuela son malos e irresponsables, aunque cabe destacar que el absentismo y otros problemas escolares, de hecho, aparecen en casi todas las familias gitanas. Lo que quiero subrayar en este punto es la diferencia que existe entre el discurso reproducido entre ellos hacia los payos, y la práctica que realmente refleja sus modelos culturales. Resulta que entre los hombres gitanos (la inmensa mayoría de mis informantes) el tema de la escuela no surge de manera espontánea. Este fenómeno observado me lo confirmó Damián, un informante clave, de la siguiente manera.

A ver, cosas del colegio no es un tema que se suele hablar. Simplemente yo te hablo de mí, yo me preocupo de que mi hija vaya al colegio, de que mi hija intente mejorar los estudios pero tampoco me he planteado que el día de mañana mi hija estudie y se esfuerce y tenga una carrera, no me lo he planteado, ¿vale? Ese es un gran problema para los que están a base dentro de la sociedad, porque vivimos al día, en el presente, no pensamos en el futuro ni en el mañana, y no es un tema que se converse 


\section{perifèria}

Número 6, Julio 2007

www. periferia. name

entre los gitanos, por lo menos yo no lo he visto.

Puede que en la actualidad haya más oportunidades académicas y sociolaborales para los gitanos, tal como arguyen las organizaciones pro-gitanos, y puede que ésta sea la única vía, tal como dicen los mismos gitanos, para mantener su nivel de vida en el futuro. Sin embargo, cambiar la estructura de pensamiento, cambiar las formas de organización de la producción social y la reproducción cultural de un colectivo requiere tiempo. Los gitanos parecen ser conscientes de los cambios que tienen que asumir en el futuro próximo.

...nosotros, el pueblo gitano, tenemos que cambiar la mentalidad, los padres tenemos que cambiar a los hijos la mentalidad. Un niño gitano que no saca buenas notas no es castigado. Luego, ¿qué motiva a ese niño a estudiar? Nada. Y luego, nosotros estamos mentalizados de que no van a ser abogados, ni van a ser médicos, ni cirujanos...

Otro aspecto relacionado es el desarrollo de la identidad durante la adolescencia. Los gitanos, en la Secundaria, no encuentran perspectiva futura ni referentes atractivos en el contexto escolar; mientras que otros contextos como la familia/comunidad, el trabajo y el ocio (consumo) pueden ofrecerles tanto sentido como perspectiva y elementos constitutivos a su identidad como adolescentes gitanos. El instituto Ausiàs March no tiene prácticamente ningún espacio académico o extraacadémico donde los valores, normas o manifestaciones cotidianas de la cultura gitana y la cultura adolescente gitana se puedan valorar; ni otros espacios donde la identidad escolar y la sensación de pertenencia se comunique a este alumnado. Este hecho conduce al fenómeno que provoca que la actitud contraescolar, el rechazo de los valores y las normas de la educación formal formen parte y alimenten una identidad gitana adolescente.

Luís, un joven absentista explica cómo dejó de ir a la escuela en los primeros meses.

Bueno, escúchame, escúchame, tío. Estás con tus colegas, ¿no? Estás con tus colegas. Ya vas, ya vas por tus colegas, a lo mejor, pero venga va. Pero si no están tus colegas allí, ¿qué haces tú sólo allí? [...] sólo. [yo estaba durante algunos meses en el instituto] pero no hacía nada. Lo hacía el otro. Yo le estaba mirando. ¿Vale? [...] y haz esto. Y me lo hacía. [ENT: ¿Y qué dijeron los profes?] Nada. No se enteraron. No se enteraron. 


\section{perifèria}

Número 6, Julio 2007

www. periferia. name

Colate, igual que Luís figura en las listas del Ausiàs March, pero él nunca pisó la escuela secundaria, ni tan solo un día.

Colate: Yo fui al instituto. Yo fui a matricularme.

ENT: ¿Tú sólo o con padres?

Colate: Sí, con amigos.

ENT: Con los amigos. Y fuisteis y ¿qué?

Colate: Me matriculé nada más. Y ya no llegué a apuntarme

ENT: ¿Por qué?

Colate: Porque ya vine de Francia y ....

ENT: ¿Cómo? ¿En el verano fuiste a Francia?

Colate: Sí. Yo fui a Francia antes de empezar el colegio, y ya un mes falté. Un mes y ya no fui ya.

ENT: ¿Ya no te dejaron entrar?

Colate: Ya no quería ir allá. (...)

El absentismo, el comportamiento disruptivo y, en general, el distanciamiento de las normas escolares forman parte del conjunto de respuestas elaboradas a los mensajes del entorno social (familia, comunidad local, escuela, prensa, etc.) y a las experiencias propias sobre la desigualdad de oportunidades escolares y sociolaborales. Las bajas expectativas académicas sobre sí mismos - consecuencias de los mensajes ambivalentes de los agentes sociales - hacen que los niños y niñas busquen alternativas de éxito en otros ámbitos de la vida. 0 , dándole la vuelta, las oportunidades futuras - atractivas y reforzadas por una serie de referentes - hacen que la escuela, donde la competencia es dudosa y cuestionable, no sea un lugar agradable ni necesario para el futuro. Chucho, por ejemplo, pondera racionalmente su futuro y decide que el "demasiado rollo" del instituto no tiene sentido para conseguir un trabajo, "lo que sea", tal como han hecho sus amigos y su hermano.

ENT: ¿Qué hará el Chucho de treinta años?

Chucho: Estará trabajando. Cuando cumpla los dieciséis ya me meteré en un cursillo.

ENT: ¿En qué cursillo?

Chucho: Yo qué sé. Algo de paleta o todo, lo que sea.

ENT: Pero para hacer esto, ¿no tienes que tener el graduado escolar? 


\section{perifèria}

Número 6, Julio 2007

www. periferia. name

Chucho: No. Que yo sepa, mi hermano allí está.

Observando los pocos (aunque cada vez más) casos de continuidad académica, podemos ver que muchos de estos adolescentes han intentado incorporar ciertos elementos de una nueva estructura de oportunidades del sistema educativo. La participación en agrupaciones pro-gitanas indudablemente ayuda en la mitigación de los roles aparentemente contradictorios, como el de ser niña-adolescente gitana, y el de seguir los estudios sin compañeros gitanos, lejos del hogar, dedicándole más tiempo que a la familia. En este sentido, los niños y las niñas que consiguen este rol de intermediario dan una respuesta adaptativa individual a las oportunidades, reconociendo y actualizando las informaciones sobre las vías de futuro posibles; y por supuesto, al mismo tiempo, reconociendo el poder restringente de las normas de la comunidad (fuerzas comunitarias en el concepto de Ogbu 2004). En muchos casos su gran mérito no es el reconocimiento de estas fuerzas, sino la capacidad de negociar entre las nuevas oportunidades y las normas de la comunidad, o bien, entre la modernidad y el conservadurismo.

Durante el trabajo de campo dos alumnos gitanos, una chica y un chico, pasaron al bachillerato. Sandra, que en tercero de ESO perdió un año por culpa de la presión del grupo de iguales gitanos, ahora cursará su segundo año en la universidad. Parece que ella salió más fuerte y decidida del fracaso temporal. Por el contrario, Aurelio que no presentó problemas durante la ESO y recibió apoyo incondicional por parte de su familia y profesores, no pudo aguantar la doble presión de su grupo de iguales y el miedo al futuro desconocido, así pues "renunció" al inicio del bachillerato. Ahora trabaja como peón de la construcción, está casado y no piensa volver a estudiar. Los dos recibieron un apoyo activo por parte de una fundación pro-gitana, tanto para lo referente a sus estudios diarios, como en su difícil negociación entre la comunidad y la escuela.

Lo que cabe destacar en el caso de Badalona es que, tal como sugiere Ogbu respecto a la población afroamericana en los Estados Unidos, la comunidad gitana, y especialmente los niños y niñas, asumen el bajo rendimiento escolar como una forma "natural" de la desigualdad de oportunidades académicas y laborales. El sistema desigual, consecuentemente, genera una respuesta colectiva de la 


\section{perifèria}

Número 6, Julio 2007

www. periferia. name

comunidad gitana, que no apoya el desarrollo de una identidad estudiantil, sino más bien provoca resistencia o actitudes de rechazo ante los valores, normas y conocimientos escolares. Una respuesta colectiva que, por un lado, adapta los esfuerzos y preferencias a las oportunidades, y por el otro, a través de la resistencia, afirma el contenido étnico de la identidad de los niños y adolescentes. La continuidad académica individual requiere una renovación de los modelos culturales y, en algunos casos, el rechazo parcial o total de éstas. Pero esta vía todavía no es dominante entre las y los gitanos de Badalona.

\section{El caso de Bogotá}

La kumpania10 rom de Bogotá está constituida por dos familias numerosas y una más pequeña. Se trata aproximadamente de trescientas personas, la mayoría de las cuales se concentran en tres barrios vecinos. Los abuelos de los niños y niñas de edad escolar fueron refugiados de países de la Europa del Este (sobre todo Rusia y Grecia) y según la memoria colectiva escaparon en barco del exterminio nazi, o, en otra versión, llegaron a España y de allí tomaron el camino hacia el nuevo continente. Pero no son ellos los primeros rom que aparecían en la historia de la República, ni de Bogotá. Los rom que nacieron en Colombia se sienten colombianos y lo comentan con mucho orgullo, aunque su identidad étnico-cultural gitana está subrayada en todo momento. Todos y todas - excepto la familia pequeña cuya trayectoria diverge de las dos grandes - son bilingües, pero los adultos utilizan más la lengua romaní que los más jóvenes.

Sus principales actividades productivas son el comercio y el trabajo artesano e industrial con metal en talleres (garajes) propios. Las mujeres suelen salir a centros comerciales o a ferias, a leer la mano, acompañadas por sus hijas. Una parte importante de la comunidad - sobre todo los ancianos - no tiene estudios formales, otros tienen alguna experiencia en el colegio, aunque esto no es de sorprender porque en Colombia la escolarización sólo es obligatoria formalmente pero no en la práctica y hasta hace algunos años la escuela pública era poco accesible para los

\footnotetext{
${ }^{10}$ Kumpania: el conjunto de la población rom de un territorio geográfico (aunque es un concepto mental, más que geográfico)
} 


\section{perifèria}

Número 6, Julio 2007

www.periferia. name

pobres. Además, las familias rom hace sólo algunas décadas que comenzaron a asentarse y a vivir en casas propias o arrendadas, antes viajaban alrededor de la República tocando territorios de países vecinos, como por ejemplo Ecuador o Venezuela.

La mayoría de las familias rom de Bogotá no es pobre, pero sí que hay algunas. Los más ricos también tienen problemas financieros momentáneos porque la acumulación de bienes no es habitual y en algunos casos hasta las viviendas se compran y venden con cierta frecuencia.

Las relaciones interétnicas pueden definirse como buenas. Jóvenes y adultos coinciden en decir que "los gadyé nos quieren". Sin embargo, la comunicación interétnica está pautada de manera más o menos estricta por parte de los rom. Los rom mantienen una cierta distancia con los gadyé, pero entablan buenas relaciones personales y de negocio. Los jóvenes tienen más amigos entre los gadyé que sus padres.

Sumamente, cuando estaban nuestros padres, nuestros padres nomás lo que trataron con los gadyé era hacer el negocio y no hablar más. Hacer el negocio, coger el dinero y no te veo, hasta luego y ya. Pero hoy en día, ya tenemos amigos, ya nos quiere mucho la gente aquí en los barrios. En las ciudades donde llegamos, o en pueblos, 'uy, llegaron los gitanos'. Y la gente habla muy bien con nosotros porque ya que nosotros tenemos respeto a ellos, ellos respetan a uno. Y la mayoría de nuestros vecinos bien contentos y felices con nosotros. Y la gente también nos quiere mucho porque no nos metemos con ellos, ni ellos se meten con nosotros. Sino nos respetan y los respetamos. Somos muy tratables con ellos, y ellos también son muy tratables con nosotros. Ya uno no 'rescrimina'. Y ya no dicen a uno 'igitano!' con 'rescriminación'. Hoy en día le llaman a uno por su nombre, pero igual saben que uno es gitano.

La relación interétnica entre rom y gadyé es más bien controvertida debida a la representación negativa de los gitanos que está presente en la sociedad, pero pocas personas colombianas tienen experiencia personal con los rom y en la actualidad hay pocos casos de conflicto interétnico. Los investigadores colombianos junto con los activistas rom arguyen que la invisibilidad total hace que el pueblo colombiano conozca a los gitanos, más bien de las leyendas, y en base a la 


\section{perifèria}

Número 6, Julio 2007

www. periferia. name

realidad. De todas formas en este sentido, PROROM11, la asociación rom, ha conseguido un amplio reconocimiento de este grupo étnico por parte del Estado. Gracias a esto, en todas las políticas, antiguas y nuevas, referentes a los grupos étnicos del estado, los rom están incluidos, junto con los indígenas, los afro colombianos y los Raizal.

La sociedad colombiana es una sociedad multiétnica en la que - a pesar del discurso adverso - el origen "racial"/étnico estratifica el sistema de oportunidades educativas y laborales, aunque no de manera absolutamente determinante. En este sentido, los rom de origen europeo, por su apariencia fenotípica, tienen una ventaja social frente a, por ejemplo, los afrocolombianos o los indígenas. En Colombia, los rom no son identificables por su apariencia, por lo cual los hombres, niños y niñas no sufren discriminación automática en los espacios públicos, ni en la escuela. Las mujeres por su prenda tradicional y, particularmente, por su dedicación productiva sí pueden ser objeto de discriminación o rechazo.

En cuanto a la situación educativa, la legislación del Estado colombiano, la recién iniciada "revolución educativa" (es decir reforma) de la Alcaldía de Bogotá, asegura el desarrollo de una educación formal que respeta e incorpora las necesidades educativas de cada grupo étnico en el marco de la escolarización pública. La Etnoeducación es la principal política educativa de Colombia para la inclusión de los grupos étnicos en el sistema educativo. Hasta la fecha, se han elaborado muy pocos proyectos concretos en este respecto con el grupo rom. Hay que destacar, sin embargo, el trabajo que se ha comenzado entre el Ministerio, los municipios y los rom para establecer las bases y los principios de una futura política etnoeducativa concreta.

\section{Escuela}

En 2005 realicé una observación participante de dos meses en una escuela de Bogotá que disponía del número más alto de alumnado rom de la ciudad, y que se encontraba en la frontera de los barrios que habita la mayoría de la kumpania.

\footnotetext{
${ }^{11}$ Proceso Organizativo rom (Gitano) de Colombia
} 


\section{perifèria}

Número 6, Julio 2007

www. periferia. name

Durante el año académico 2005 (febrero - diciembre) dieciséis niñas y niños rom cursaron estudios en esta escuela, entre el grado 0 (5-6 años) y el grado 9 (14 años). Aunque los profesores sabían que había algunos alumnos "gitanos", porque sus mamás vestían "de gitana", la cultura rom y los derechos que surgen de su estatus étnico eran absolutamente ignorados en este contexto. Consecuentemente la escuela no se sentía obligada a desarrollar su proyecto etnoeducativo ni a garantizar los principios prescritos por la ley para asegurar el desarrollo apropiado de la lengua y la identidad cultural del alumnado procedente de grupos étnicos. Cuando pregunté por ello, un profesor de castellano respondió con un paralelismo: "Si un grupo de británicos se instala en Bogotá, la escuela del barrio no está obligada a iniciar una educación bilingüe." El comentario pone en evidencia el desconocimiento absoluto de los rom como grupo étnico - uno de los cuatro de la República - con derechos especiales reconocidos.

\section{Padres y madres}

Respondiendo a la pregunta del etnógrafo, todos los padres estaban de acuerdo en la importancia de los estudios en el progreso económico y en la movilidad social futura, pero en la práctica, sólo en algunos casos podía comprobarse que la escuela formaba parte de una proyección sociolaboral concreta. Por ejemplo, en un mismo núcleo familiar, Yoshka buscaba una escuela privada femenina para sus hijas, para que pudieran seguir estudiando sin que los rom las criticasen, mientras que su hermano Pintuco sacó a su hija del colegio después de tan solo cuatro meses del primer año de escolaridad. La escolarización de las niñas es un tema más delicado y en la práctica los padres son más estrictos con ellas que con sus hijos varones. Algunos padres arguyen que los estudios son imprescindibles porque ya no se puede vivir del trabajo manual, otros dicen que "nosotros los rom siempre hemos encontrado la forma de ganarnos la vida" y esto será así en el futuro con o sin estudios. A pesar de las reivindicaciones oficiales de PROROM (asesorada por un antropólogo militante de movimientos sociales), lo que la mayoría de los padres realmente desea es tener una escuela primaria para los rom, es decir un lugar donde sus hijos aprendan a leer y escribir, matemáticas, informática y estudien su propia cultura en su lengua propia. 


\section{perifèria}

Número 6, Julio 2007

www. periferia. name

\section{Niños y niñas}

En el contexto escolar los niños y niñas rom no revelan su pertenencia étnica, no hablan en romaní y no dan conocer sus costumbres, aunque tampoco lo ocultan. Son uno más entre los alumnos y alumnas. Incluso sus mejores amigos desconocen el significado de la palabra "rom". Los niños y niñas rom, mientras acuden al colegio, son relativamente buenos estudiantes. En Primaria, la coordinadora "tenía mucha experiencia con los gitanos12" y acusaba a los padres que no respetaban las normas de la escuela, comentario que no he escuchado de ningún otro profesor de manera tan directa. Algunos, anecdóticamente, explicaban que no es que tuvieran problemas con los gitanos, sino que, precisamente ellos, eran los mejores estudiantes de todo su grupo. Hecho que no se ha comprobado una vez revisadas las notas generales de éstos.

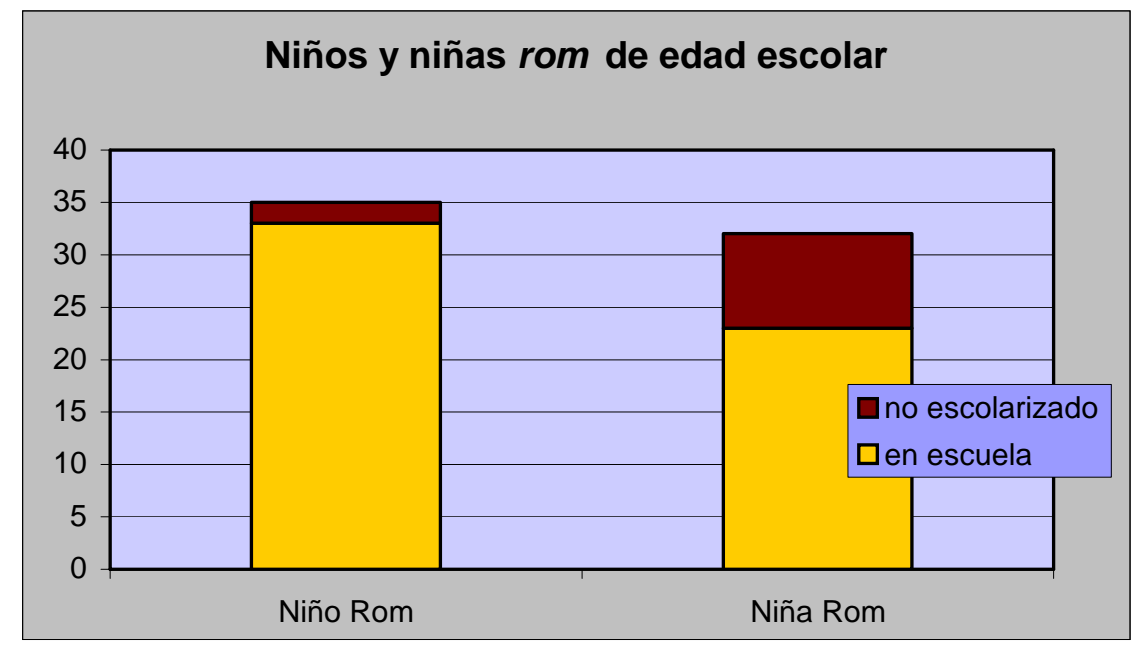

Gráfico 3: Proporción de niños y niñas rom de la kumpania de Bogotá de edad escolar que van y que no van a escuela (2004). Fuente: Elaborado por el autor a partir de estadísticas de PROROM y correcciones propias

\footnotetext{
12 Los rom en Colombia se conocen por la gente como "gitanos". La denominación "rom" se introdujo
} recientemente en su movimiento político-cultural para evitar las connotaciones anecdóticas y negativas. 


\section{perifèria}

Número 6, Julio 2007

www. periferia.name

A los chicos rom les gusta ir a la escuela y aquellos que van no suelen faltar. Hay, sin embargo, proporcionalmente menos chicas $(72 \%$ del total chicas rom de edad escolar) en la escuela que chicos ( $94 \%$ del total chicas de edad escolar), y con el avance de la edad esta proporción se intensifica aún más. Fui testigo de un caso donde los padres de una estudiante rom del quinto grado, muy popular entre los compañeros gadyé del grupo, decidieron retirarla de la escuela. Gracias a la intervención de la tutora y como consecuencia de la depresión aparente de la niña, los padres le permitieron unos meses más de estudios, pero en junio acabó definitivamente su escolaridad. Una historia bastante general, pero, curiosamente, hasta mi trabajo de campo en la escuela los profesores no se habían dado cuenta de la pérdida sistemática de las niñas gitanas y por tanto no habían actuado de ninguna manera para prevenirlo. Finalmente, en el mismo año, esta niña y su familia se fueron a Argentina para visitar a unos familiares y probar suerte. La realización de viajes largos y lejanos por parte de la familia rom es un motivo común para suspender los estudios. Pertenece también a esta realidad la trayectoria de algunos pocos jóvenes que con títulos universitarios han elegido distintos niveles de aculturación en las formas gadyé de trabajar, organizar sus relaciones y responder a las oportunidades sociolaborales.

En resumen, lo más destacable en el caso bogotano es que los rom han optado por la escolarización - desde hace poco tiempo - voluntariamente. Ya que son una parte de su estrategia general de cara a la sociedad mayoritaria, los modelos culturales respecto a la escuela no están cristalizados y por tanto muestran una gran heterogeneidad intraétnica. Los niños y niñas rom, en el contexto escolar no destacan su pertenencia étnica y no muestran comportamientos contra-escolares, supuestamente porque en la vida cotidiana las fronteras étnicas están claramente marcadas y no necesitan entablar relaciones dicotómicas para mantener estas fronteras. 


\section{perifèria}

Número 6, Julio 2007

www.periferia. name

\section{Discusión}

\section{Respuestas de la antropología de la educación}

Desde el principio del trabajo de campo en Badalona me planteaba la pregunta: Si el éxito y el fracaso académico principalmente - aunque no únicamente - están definidos por factores históricos y socioeconómicos, entonces ¿los gitanos fuera de Europa tienen una relación diferente con la escuela?

La corta historia de la antropología de la educación ofrece fundamentalmente dos explicaciones al rendimiento desigual de grupos sociales distintos. En principio las explicaciones culturalistas (Spindler, Wolcott, Erickson, etc.) ocupaban la la mayor parte de la literatura buscando el origen de las desigualdades sociales en la diferencia cultural entre estos grupos. La discontinuidad entre la cultura del grupo y la cultura de la sociedad mayoritaria representada por la escuela crean conflictos y hacen que el conocimiento escolar sea parcial o totalmente deslegitimado por la comunidad, y en cambio el conocimiento tradicional de la comunidad se descuide o se rechace por la escuela. La discontinuidad reconocida conducía a explicaciones de privación cultural o déficit cultural. Aunque las diferencias culturales son indudables entre los grupos sociales, sin embargo, a partir de los setenta la atención de los estudiosos de formación antropológica se traspasó a otros aspectos contextuales, gracias a John U. Ogbu. Según este antropólogo estadounidense de origen nigeriano el estatus desigual y las fuerzas comunitarias producen unas diferencias culturales secundarias, es decir diferencias que son consecuencias y productos del contacto histórico y actual del grupo minoritario con la sociedad mayoritaria. Ogbu arguye que el bajo rendimiento de los afroamericanos en los Estados Unidos es una respuesta colectiva adaptativa a la estructura de oportunidades educativas y sociolaborales.

Los estudios de Ogbu y de sus seguidores sobre el rendimiento escolar de la comunidad negra de EEUU ayudan a entender ciertas dinámicas de la comunidad gitana del Estado español. Según Ogbu, los grupos minoritarios pueden clasificarse en voluntarios (inmigrantes) e involuntarios (tipo casta), dependiendo de la historia de su incorporación en la sociedad mainstream y del tratamiento ulterior de ésta 


\section{perifèria}

Número 6, Julio 2007

www. periferia. name

hacia la minoría. La minoría voluntaria o inmigrante llega con expectativas positivas, con un proyecto de futuro más o menos claro, y con un doble marco de referencia: de lo que ha dejado atrás y de lo que recibe como premio por su migración (escuela gratuita de mayor calidad, seguridad, trabajo remunerado, derechos humanos, etc.). Las dificultades que surgen en el proceso de incorporación en la nueva sociedad son asumidas como precio necesario para conseguir los objetivos de la migración. La educación, generalmente se interpreta como un espacio donde se consiguen las competencias para los éxitos futuros y por tanto representa una inversión principal. Al mismo tiempo la minoría involuntaria (o de tipo casta) adquiere su estatus minoritario, a menudo subordinado, en contra de su voluntad (a través de conquista, colonización, esclavitud, etc.) y su único marco de referencia se restringe a la relación desigual con la sociedad mayoritaria. Los padres y los alumnos de la minoría involuntaria mantienen expectativas más bajas sobre la escuela y la educación formal, y sus modelos culturales ofrecen estrategias alternativas para conseguir éxito en la vida. Los fracasos académicos iniciales se asumen como consecuencia de la relación de desigualdad entre ellos y la sociedad mayoritaria (prejuicios, discriminación) y como respuesta se desarrolla una actitud contra-sistema.

En relación con los gitanos de Badalona me parece revelador utilizar la categoría ogbuiana de la minoría involuntaria.13 Los gitanos a lo largo de su historia europea han sido objeto de hostilidad, recelo y rechazo por parte de la sociedad que definía su incorporación subordinada y marginal. En cuanto a sus oportunidades presentes, hemos de tener en cuenta que las nuevas oportunidades educativas y laborales en realidad son accesibles sólo para una parte limitada de los gitanos. Mientras la legislación y las políticas educativas y sociolaborales promueven formalmente la participación más activa de la gente gitana, por otro lado, los propios agentes sociales (profesores, vecinos, prensa, políticos...) no están preparados para una

\footnotetext{
13 La primera investigadora europea que llama la atención sobre la aplicabilidad de este modelo a los gitanos europeos es Sílvia Carrasco (2002), aunque más adelante es utilizada por otras estudiosas como Pontrandolfo (2004) o Jane Dick Zatta (2003).
} 


\section{perifèria}

Número 6, Julio 2007

www. periferia. name

práctica más inclusiva y para la comunicación de esta actitud a través de mensajes inequívocos14 hacia la comunidad gitana española.

Ogbu habla de un time-lag, un retraso temporal, entre los cambios en la estructura social y la modificación de las respuestas colectivas, es decir el cambio de modelos culturales de la minoría. Aunque, gracias a los movimientos reivindicativos gitanos y a la política social de Europa, se abren nuevas vías para redefinir y al mismo tiempo reforzar la identidad étnica que históricamente está vinculada a una situación social y económica marginal; sin embargo la mayoría de las familias y personas gitanas se autodefinen a partir de ciertas diferencias culturales secundarias desarrolladas en otra época (un pasado próximo) de las relaciones interétnicas. Siguiendo el modelo ecológico-cultural de Ogbu, los gitanos españoles, como una minoría involuntaria afrontan problemas escolares que en última instancia conducen a la deserción (desde el punto vista de la escuela: fracaso académico). La desvinculación puede interpretarse como una respuesta adaptativa a la realidad sociolaboral, es decir una reacción lógica reconociendo la imposibilidad de acceder a estudios más avanzados y a puestos de trabajos mejor remunerados. A esto añadiría un aspecto: la actitud contra-escolar que como una práctica de la diferencia cultural secundaria apoya activamente el mantenimiento y la reproducción de la identidad étnica. Esto se entiende aún más observando que la escuela hasta ahora no ha podido apoyar paralelamente el éxito académico y el mantenimiento o reconstrucción de ciertos elementos étnicos de la identidad del alumnado gitano.

14 Abajo (1997) y Abajo - Carrasco (2004) llama la atención a la importancia de los mensajes inequívocos positivos mantenidos a lo largo del tiempo, como condición para la continuidad académica 


\section{perifèria}

Número 6, Julio 2007

www. periferia. name

La analogía "afroamericano - gitano español" nos ayuda entender algunos aspectos de la situación educativa de estos últimos, sin embargo, ni la categoría involuntaria, ni la minoría inmigrante se ha comprobado útil en el caso de los rom colombianos. Dado que se trata de la segunda o la tercera generación de europeos refugiados se daría con facilidad esta segunda categoría y así podríamos mostrar de manera comparativa dentro del mismo grupo étnico la tesis de que la minoría involuntaria muestra peor rendimiento académico, que la minoría voluntaria (que de hecho estaba presente entre las hipótesis de trabajo previas al segundo trabajo etnográfico en Bogotá). Sin embargo, los rom de Bogotá no cumplen varios requisitos de esta categoría y este hecho aporta una nueva prueba a las críticas que encontraba la categorización dicotómica de Ogbu demasiado cerrada y reduccionista. Entre otros seguidores de Ogbu, Margaret A. Gibson recomienda la matización de estas agrupaciones para que se dé cuenta de la gran diferencia entre modelos migratorios, grupos inmigrantes, la heterogeneidad intragrupal y para que variables como el género o la clase social puedan ser más acentuadas en el análisis. Gibson y Ogbu en 1991 editaron el famoso Minority status and schooling, una serie de estudios comparativos sobre diferentes grupos minoritarios en contextos variados para ofrecer nuevos aspectos que mejorasen el modelo ecológico-cultural de Ogbu. Gibson y Bhachu (autores de esta recopilación), por ejemplo, demostraron que los inmigrantes Sikh en un contexto rural californiano desarrollan unas estrategias educativas y teorías de éxito muy parecidas a las estrategias y teorías folk de los inmigrantes Sikh en un contexto urbano británico. Pero al mismo tiempo, demostraron cómo un grupo pequeño de Sikh en Inglaterra elabora respuestas más parecidas a las minorías involuntarias. Yangsook Lee, en el mismo volumen, comparó el rendimiento educativo de la minoría involuntaria coreana en Japón y la minoría inmigrante coreana en los Estados Unidos. El primer grupo afronta una recepción hostil y discriminatoria de parte de la sociedad japonesa y como consecuencia su escolarización es conflictiva, entre otros, a nivel de rendimiento y de convivencia interétnica. En cambio, en los EEUU los coreanos están entre los grupos más reconocidos por su rendimiento alto, y los profesores y los compañeros mantienen unas expectativas muy altas hacia ellos, influyendo así positivamente en sus autoexpectativas. Nobuo K. Shimahara, por su parte, explica 


\section{perifèria}

Número 6, Julio 2007

www. periferia. name

cómo un grupo social marginado en el pasado de la historia japonesa, ha cambiado su actitud y su práctica ante la educación escolar a través de la reciente apertura de las oportunidades de movilidad social.

Estos y otros estudios del libro analizan, por un lado, grupos de origen común que reaccionan de manera parecida a la escolarización en destinos distintos de la migración, o bien grupos que en un estatus desigual involuntario desarrollan estrategias diferentes que en un estatus desigual minoritario voluntario.

\section{Resultados}

En mi presente comparación, en cambio, se trata del mismo grupo étnico en contextos históricos y socio-culturales muy diferentes, pero con unas respuestas muy parecidas hacia la escuela (aunque con una heterogeneidad significativa en ambos grupos).

En los dos casos hemos podido observar que en líneas generales las respuestas colectivas de la comunidad gitana de Badalona y de los rom de Bogotá ante la escuela son parecidas.

Mientras que en España los gitanos desde hace siglos sufren un estatus subordinado y marginado en la sociedad, en Colombia los rom gozan de una ventaja social frente a otras minorías históricamente oprimidas, también por su apariencia fenotípicamente europea. En Colombia, los rom se reconocen como un grupo étnico y por tanto privilegiado en ciertos contextos legislativos, entre otros en el educativo.

En cuanto al modelo cultural elaborado en lo que respecta a la educación formal, los rom de Bogotá, igual que los gitanos de Badalona, tienen una gran apertura retórica hacia la escuela y las oportunidades futuras que permiten los estudios. También coinciden en las prácticas heterogéneas con una dominancia conservadora. Todos los padres se preocupan más por la escolarización de las niñas, por la amenaza que representa la escuela para ellas. En Bogotá la desescolarización de niñas no es excepcional, mientras que en Badalona las autoridades intervienen en casos parecidos. 


\section{perifèria}

Número 6, Julio 2007

www.periferia. name

La deserción prematura de la escuela es común entre los dos grupos gitanos/rom, no obstante se ve una diferencia importante en la participación escolar. Los rom bogotanos no presentan una actitud contra-escolar o comportamiento disruptivo. Quizá el contexto social ofrezca oportunidades para desarrollar una identidad étnica fuerte (lengua propia, comunidad rom estable, bajo nivel de competencia económica directa, etc.) basada en la fluidez de las relaciones con la sociedad mayoritaria y no en la problematización de éstas a través de conflictos y la reafirmación de las diferencias étnicas a lo largo de unas fronteras.

Los profesores de Bogotá - como la sociedad en general - comparten unos conceptos estereotipados y negativos sobre los gitanos, pero no los vinculan directamente a los alumnos rom, no necesitan acudir a estas justificaciones, porque los alumnos rom no crean sistemáticamente dificultades al profesorado. Por otro lado, los profesores muestran una pasividad total ante el abandono escolar en el paso de Primaria a Secundaria. Ni se dan cuenta: de manera parecida al instituto observado de Badalona. En Badalona los profesores sí justifican los conflictos escolares alrededor del alumnado gitanos a través de las diferencias culturales entre la mayoría y los gitanos.

Otra coincidencia es que los dos casos han presentado - en su heterogeneidad interna - vías individuales alternativas, desde el abandono hasta la carrera universitaria; desde los modelos tradicionales de seguir las pautas culturales hasta el aislamiento de la comunidad, de sus normas y valores.

\section{Conclusión}

Para concluir quiero subrayar el hallazgo más destacado de la comparación. Se trata de un grupo étnico (los gitanos - rom) que en contextos socioculturales e históricos muy diversos mantienen una actitud bastante similar ante la educación escolar. Esta afirmación, bajo ningún concepto quiere sugerir que "los gitanos culturalmente no son compatibles con la escuela". Pero sí, que a pesar de las oportunidades dadas en el sistema educativo catalán-español y colombiano, los gitanos/rom, como grupo (y no los individuos) actúan de manera más lenta y conservadora que otros grupos étnicos en ambos contextos. 


\section{perifèria}

Número 6, Julio 2007

www.periferia. name

Para explorar detalladamente esta similitud tendremos que buscar respuestas a las siguientes preguntas hipotéticas:

- ¿Puede que en ausencia de incentivos muy potentes, el "time lag" (Ogbu 2004) entre el cambio de la estructura de oportunidades y la negociación de nuevos modelos culturales sea más largo entre los gitanos/rom de lo que esperaríamos, y que en otras minorías?

- ¿Puede que las nuevas oportunidades escolares y laborales aparentemente atractivas ofrecidas por la sociedad mayoritaria todavía no se hayan comprobado suficientemente atractivas para los gitanos en ambos contextos?

- Debido a las interacciones activas (y estructuradas según las normas de los rom) con los gadyé, ¿los rom no necesitan reafirmar su etnicidad (fronteras étnicas) en la escuela, mientras los gitanos de Badalona la manifiestan y reafirman en el principal espacio de contacto obligatorio, en la escuela? ¿Puede ser que en el contexto bogotano las fronteras étnicas sean más firmes, y los rom tengan menos necesidad de dicotomizar la relación entre rom y gadyé en la escuela?

- En Badalona la escuela es obligatoria y la presencia está altamente vigilada por los servicios educativos y sociales, mientras en Bogotá la escuela, en la práctica, no es obligatoria (aunque legalmente sí). ¿Puede que la asistencia escolar de los rom sea una estrategia aculturativa voluntaria y sea por eso que las relaciones escolares son menos conflictivas?

- ¿Puede ser que las diferencias en la estructura social entre el Estado español y Colombia realmente no sean muy significativas en cuanto a las estrategias del mantenimiento de las fronteras étnicas de los gitanos/rom?

La escolarización del alumnado gitano en España es un tema que se ha colocado en los márgenes del interés político y científico. Desafortunadamente esto no quiere decir que se hayan encontrado las respuestas necesarias para que el pueblo gitano 


\section{perifèria}

Número 6, Julio 2007

www. periferia. name

pueda participar con igualdad de oportunidades en el sistema educativo. Las investigaciones que ponen en una dimensión comparativa la escolarización de las minorías étnicas pueden ayudar a la comprensión de qué manera habría que mejorar las circunstancias educativas y sociales para conseguir mayor participación y continuidad académica.

\section{Bibliografía}

Abajo Alcalde, José Eugenio (1997). La escolarización de los niños gitanos: el desconcierto de los mensajes doble-vinculares y la apuesta por los vínculos sociales y afectivos. Madrid: Ministerio de trabajo y asuntos sociales

Abajo, José Eugenio; Carrasco, Sílvia; (eds) \& Equipo de Investigación sobre el Éxito Escolar del Alumnado Gitano (2004). Experiencias y trayectorias de éxito escolar de gitanas y gitanos en España. Encrucijadas sobre educación, género y cambio cultural. Madrid: IM-CIDE, Instituto de la mujer

Bereményi, Bálint Ábel (2007). “Claro hijo, vaya a la escuela y si se aburre lo sacamos". Relaciones y experiencias de los gitanos de Badalona y los rom de Bogotá con la educación escolar. Tesis Doctoral - Universitat Autònoma de Barcelona. Departament d'Antropologia Social i cultural

- (2005) “Teachers' discourses about Roma Pupils' low performance", Intervención presentada en Social Inclusion And Young People - Research Seminar organizado por la Comisión Europea y el Consejo de Europa en 31.10 - 02.11.2005, Budapest

- (2004) Experiencias escolares del alumnado gitano en un barrio de la periferia de Barcelona: una aproximación etnográfica. Tesina de Máster Dirigida por la Dra. Sílvia Carrasco Pons. Programa de Doctorat d'Antropologia, Departament d'Antropologia Social, Universitat Autònoma de Barcelona.

Carrasco, Sílvia (2002). “Inmigración, minorías y educación en España. Ensayar algunas respuestas y mejorar algunas preguntas a partir del modelo de John Ogbu", Ponencia del IX Congreso de la FAAEE, Barcelona: Institut Català 


\section{perifèria}

Número 6, Julio 2007

www. periferia. name

d'Antropologia (CD-Rom, 2003)

Gibson Margaret A.; Ogbu John U. eds (1991). Minority status and schooling: A Comparative Study of Immigrant and Involuntary Minorities. New York: Garland Publishing, Inc.

Koheslan (ed.) (2007). Gitanos e inmigrantes vascos en su ciclo de vida adolescente. Un proyecto de investigación comunicativa. Universidad del País Vasco. Argitalpen Zerbitzua Servicio Editorial

Lee, Yongsook (1991). "Koreans in Japan and the United States" En: Minority Status and Schooling. A Comparative Study of Immigrant and Involuntary Minorities. New York \& London: Garland Publishing Inc.

Ogbu, John U. y Herbert D. Simon (1998). Voluntary and Involuntary Minorities: A Cultural-Ecological Theory of School Performance with Some Implications for Education.

Ogbu, John U. (2004). "Respuestas de las minorías a la experiencia escolar". En: Boletín del Centro de Documentación de la Asociación de Enseñantes con Gitanos, septiembre: Monográfico sobre «El éxito escolar de las Españolas y Españoles Gitanos/as» (éxito académico y minorías étnicas) №25/26 - Madrid: AEG

Pontrandolfo, Stefania (2004). Un secolo di scuola. I rom de Melfi. Roma: CISU

San ROMÁN, Teresa (1980). “La Celsa y la escuela del barrio” En: Escuelas, pueblos y barrios (antropología educativa). Mary KNIPMEYER; Marta GONZÁLEZ BUENO y Teresa SAN ROMÁN (eds). Madrid: Akal, p.163-263.

Shimahara, Nobuo K. (1991). Social Mobility and Education: Burakumin in Japan En: Minority Status and Schooling. A Comparative Study of Immigrant and Involuntary Minorities. New York \& London: Garland Publishing Inc.

Vargas Claveria, Julio; Gómez Alonso, Jesús (2003). “Why Romà do not like mainstream schools: voices of a people without territory" En: Harvard Educational Review. Winter, Vol.73.

Sánchez Roca, Montserrat, dir. (2005). Estudi sobre la población gitana de Catalunya: informe final. Barcelona: Generalitat de Catalunya, Departament de 


\section{perifèria}

Número 6, Julio 2007

www. periferia. name

Benestar i Familia 